\title{
ANALISIS MAHAR DALAM AKAD NIKAH
}

Oleh

Neila Hifzhi Siregar

Dosen Fakultas Syariah dan Ilmu Hukum IAIN Padangsidimpuan email : neilahifzhisiregar@iain-padangsidimpuan.ac.id

\begin{abstract}
Abstrac
The history of dowry since the Prophet Syu'aib provided opportunities for workers for eight to ten years. The dowry process since hosting, may not be determined but implicitly there must be dowry if there is already a qobul permit, it may also be determined before the marriage contract. The amount of dowry is in accordance with the ability of the prospective husband. The legal basis comes from the Qur'an and hadith. Mahar is a condition for marriage not to get married. Terms of a worship are carried out before practicing the pillars of marriage. If the condition has finished the problem, just leave the gift after the initial intercourse between husband and wife. If it is stated that the number of dowry is proud of itself if there is a large number If there is a slight sense of humiliation, especially the wife and family and the husband. As if the rich bought valuable items if they were called the price. Mentioning wrong giving, even hurting the juice is certainly getting wrong. Mention dowry or alms to describe the alms of charity, not to believe in Allah and later in the day. Mahar is paid by the husband after the first initial contact.
\end{abstract}

Kata Kunci; Analisis, Mahar, Dalam, Akad, dan Nikah

\section{A. Pendahuluan}

Sejarah tentang mahar dalam Islam, terdapat dalam surah al-Qashash ayat 27 yang menjelaskan tentang mahar dalam Islam yaitu "Sesungguhnya aku bermaksud menikahkan kamu dengan salah seorang dari kedua anakku ini, atas dasar bahwa kamu bekerja denganku delapan tahun dan apabila kamu cukupkan sepuluh tahun maka itu adalah (suatu kebaikan) dari kamu, maka aku tidak hendak memberati kamu. Dan kamu Insya Allah akan mendapatiku termasuk orang- orang yang baik." ${ }^{1}$ Nabi Syu'aib as, ingin menikahkan salah satu putrinya kepada Musa, karena Musa orang yang kuat dan amanah atas ajuan dua purinya, dalilnya sebagai berikut:

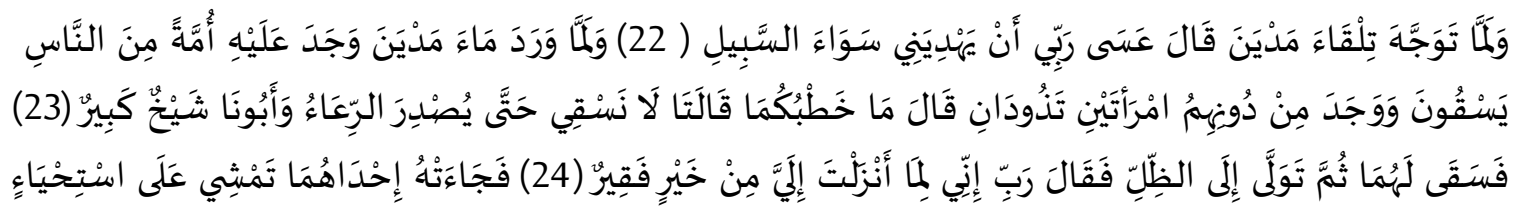

${ }^{1}$ Qs, al-Qashas, 28:27 


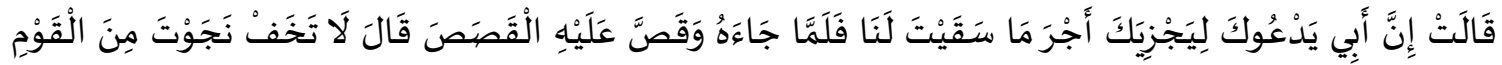

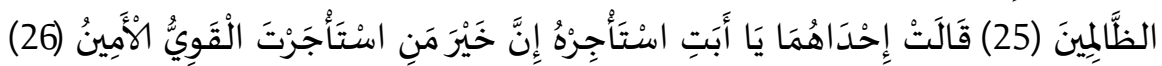

Artinya: "Dan tatkala ia menghadap kejurusan negeri Mad-yan ia berdoa (lagi): "Mudahmudahan Tuhanku memimpinku ke jalan yang benar. Dan tatkala ia sampai di sumber air negeri Mad-yan ia menjumpai di sana sekumpulan orang yang sedang meminumkan (ternaknya), dan ia menjumpai di belakang orang banyak itu, dua orang perempuan yang sedang menghambat (ternaknya). Musa berkata: "Apakah maksudmu (dengan berbuat at begitu)?" kedua perempuan itu menjawab: "Kami tidak dapat meminumkan (ternak kami), sebelum pengembala-pengembala itu memulangkan (ternaknya), sedang bapak Kami adalah orang tua yang telah lanjut umurnya. Maka Musa memberi minum ternak itu untuk (menolong) keduanya, kemudian dia kembali ke tempat yang teduh lalu berdoa: "Ya Tuhanku Sesungguhnya aku sangat memerlukan sesuatu kebaikan yang Engkau turunkan kepadaku. Kemudian datanglah kepada Musa salah seorang dari kedua perempuan itu berjalan kemalu-maluan, ia berkata: "Sesungguhnya bapakku memanggil kamu agar ia memberikan balasan terhadap (kebaikan)mu memberi minum (ternak) kami". Maka tatkala Musa mendatangi bapaknya (Syu'aib) dan menceritakan kepadanya cerita (mengenai dirinya), Syu'aib berkata: "Janganlah kamu takut. kamu telah selamat dari orang-orang yang zalim itu. Salah seorang dari kedua perempuan itu berkata: "Ya bapakku ambillah ia sebagai orang yang bekerja (pada kita), karena Sesungguhnya orang yang paling baik yang kamu ambil untuk bekerja (pada kita) ialah orang yang kuat lagi dapat dipercaya". Yang dimaksud dengan Khair (kebaikan) dalam ayat ini menurut sebagian besar ahli tafsir ialah barang sedikit makanan". ${ }^{2}$

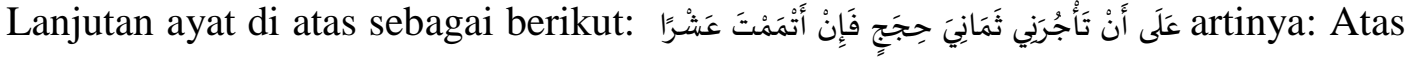
dasar bahwa kamu bekerja denganku delapan tahun dan apabila kamu cukupkan sepuluh tahun. Hukum yang berkaitan dengan ayat ini adalah tentang mahar di mana aplikasinya sebagai berikut:

1. Syarat sebelum menentukan mahar adalah kepribadian calon suami dan atau isteri yang baik dan ikhlas

2. Pekerjaan itu sebaiknya diridoi oleh Allah demikian juga calon isteri, serta calon suami mampu melakukannya dengan halal dan baik

3. Seorang calon suami harus ada dulu pekerjaan rutinnya sebelum menikah

4. Kemudian dari hasil kerjanya itu merupakan modal untuk memperoleh mahar yang akan diberikan kepada calon isterinya, serta modal hidup lanjutan setelah menikah

5. Hal ini sesuai dengan ayat berikut:

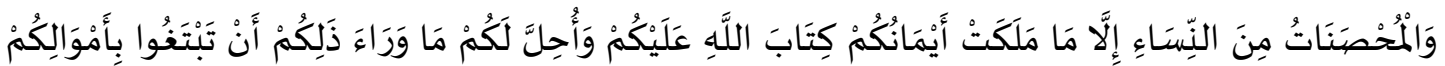

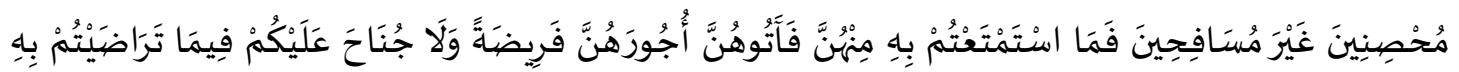

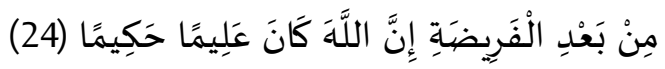

\footnotetext{
${ }^{2}$ QS, al-Qoshos, 22:26
} 
24.'Dan (diharamkan juga kamu mengawini) perempuan yang bersuami, kecuali budak-budak yang kamu miliki ${ }^{[282]}$ (Allah telah menetapkan hukum itu) sebagai ketetapan-Nya atas kamu. Dan dihalalkan bagi kamu selain yang demikian ${ }^{\text {[283] }}$ (yaitu) mencari isteri-isteri dengan hartamu untuk dikawini bukan untuk berzina. Maka isteri-isteri yang telah kamu nikmati (campuri) di antara mereka, berikanlah kepada mereka maharnya (dengan sempurna), sebagai suatu kewajiban; dan tiadalah mengapa bagi kamu terhadap sesuatu yang kamu telah saling merelakannya, sesudah menentukan mahar itu. Sesungguhnya Allah Maha Mengetahui lagi Maha Bijaksana. Maksudnya: budak-budak yang dimiliki yang suaminya tidak ikut tertawan bersama-samanya". ${ }^{3}$

6. Harus didengar oleh calon suami dan calon isteri atas ajuan dua orangtua dan calon isteri

7. Manfaatnya agar bertanggungjawab kedua belah pihak atas tawaran, serta jawaban calon suami dapat di dengar calon isteri, apakah serius datu masih jawaban tanggung

8. Besaran mahar dalam ayat ini sekedar menggambarkan syarat akad nikah, bukan harus seperti itu besarannya dan caranya seperti kerja 8 tahun sampai 10 tahun, hasilnya kambing yang banyak yang dijadikan mahar

9. Jadi benar bahwa mahar itu syarat nikah bukan rukun nikah, karena jaraknya 10 tahun antara penentuan mahar dengan akad nikah

10. Apabila wajib disebutkan saat akad nikah, tentu harus ada dalilnya yang mendukungnya, seperti bunyinya: Aku Nikahkan kepadamu si ... dengan mahar aku kerja 8 -10 tahun duluan dan upahnya kambing yang banyak tunai.

11. Jumlah mahar harus disesuaikan dengan kemampuan calon suami juga

12. Mahar pada zahirnnya membuat beban kepada calon suami, tetapi hakikatnya suatu kebaikan, hal ini diperjelas lanjutan ayat فَمَنْ عِنْدِكَ وَمَا أُرِيدُ أَنْ أَشُقَّ عَلَيْكَكَ artinya: maka itu adalah (suatu kebaikan) dari kamu, maka aku tidak hendak memberati kamu

13. Maksud suatu kebaikan adalah, di mana mahar itu merupakan modal kerja untuk hidup kedepan yang lebih baik, dibandingkan dengan hidup bersama dua orangtua,

14. Akibat baiknya mereka hidup sakinah mawaddah wa rahmah serta kedua belah orangtua senang, bahagia, puas, karena berhasil mendidik anak yang tangguh iskhlas dan ridha Allah;

15. Semakin cepat terasa enaknya menikah, bukan bersama dua orangtua;

16. Karena perempuan hidup lama bersama orangtua menjadi fitnah kenapa tidak laku, apakah karena ...

\footnotetext{
${ }^{3}$ Qs, an-Nisa', 4:24.
} 
17. Tetapi hidup bersama suami sangat terpuji, mendapatkan anak shaleh dan shalehah, rezki yang halal, jauh dari dosa zina, dan tertutup ointu pacaran dan lainnya;

18. Makanya mahar apabila disepakati boleh diberikan isteri kepada suaminya apabila diperlukan untuk makanan, apalagi untuk modal hidup dalilnya sebagai berikut:

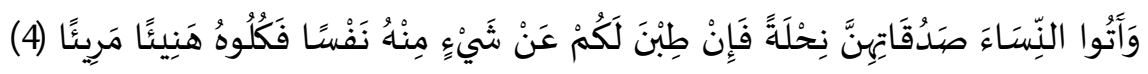
4. "Berikanlah maskawin (mahar) kepada perempuan (yang kamu nikahi) sebagai pemberian dengan penuh kerelaan ${ }^{[267]}$. Kemudian apabila mereka menyerahkan kepada kamu sebagian dari maskawin itu dengan senang hati, maka makanlah (ambillah) pemberian itu (sebagai makanan) yang sedap lagi baik akibatnya. 267]. Pemberian itu ialah maskawin yang besar kecilnya ditetapkan atas persetujuan kedua pihak, karena pemberian itu harus dilakukan dengan ikhlas". ${ }^{4}$

19. Kemudian secepatnya mampu hidup mandiri untuk mengabdi kepada dua orangtua, kirabat dan lainya dalinya sebagai berikut:

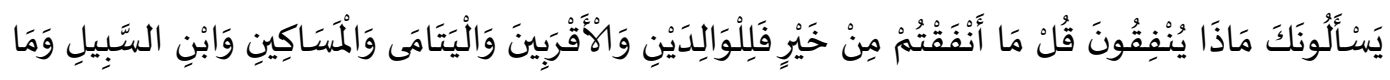

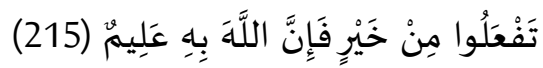

215. "Mereka bertanya tentang apa yang mereka nafkahkan. Jawablah: "Apa saja harta yang kamu nafkahkan hendaklah diberikan kepada ibu-bapak, kaum kerabat, anakanak yatim, orang-orang miskin dan orang-orang yang sedang dalam perjalanan." Dan apa saja kebaikan yang kamu buat, maka sesungguhnya Allah Maha Mengetahuinya".

20. Manusia yang terbaik adalah manusia yang terbanyak memberikan manfaat kepada dua orangtuanya dan manusia lainnya;

21. Potongan ayat selanjutnya adalah jaminan Allah atas perlakuan pinangan dan penentuan mahar yang disepkatai adalah إنْ شَاءَ اللَُُّ مِنَ الصَّالِحِينَ artinya: Kamu Insya Allah akan mendapatiku termasuk orang- orang yang baik;

22. Sejarah membuktikan Musa menjadi Nabi, mampu melawan musuh Allah yaitu Fir'aun dan bala tentarnya, banyak Bani Israil menjadi Muslim, selamat dari kejaran Fir'aun, menerima kitab Taurat sebelumnya menerima Shuhuf;

23. Kata shilihin adalah jama' berarti dua pengantin dan ditambah dengan kirabat mereka berdua seharusnya mampu mensolihkannya setelah menikah, jangan menjadi pengkhianat dan pemisah dua keluarga;

24. Istilah lain jadilah kalian berdua jahit menemukan yang berpisah, jangan menjadi sepert gunting alat perobek yang menyatu;

\footnotetext{
${ }^{4}$ Qs. an-Nisa', 4:4.

${ }^{5}$ Qs. al-Baqarah, 2:215.
} 


\section{B. Proses Mahar}

Proses menentukan mahar dalam ajaran Islam sudah sangat jelas dijelaskan sebagaimana degan tegas diabadikan adalam al-Qur'an yang berbunyi sebagai berikut :

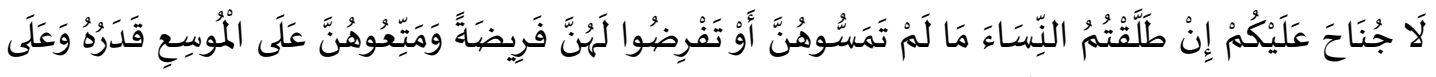

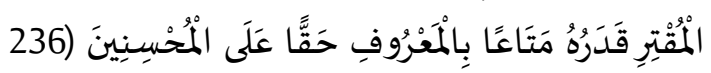

Artinya: "Tidak ada kewajiban membayar (mahar) atas kamu, apabila kamu menceraikan isteri-isteri kamu sebelum kamu bercampur dengan mereka dan kamu belum kamu menentukan maharnya (sebelum akad nikah). Dan hendaklah kamu berikan suatu mut'ah (pemberian) kepada mereka. Orang yang mampu menurut kemampuannya dan orang yang miskin menurut kemampuannya (pula), yaitu pemberian menurut yang patut. Yang demikian itu merupakan ketentuan bagi orang-orang yang berbuat kebaapabilan". Dari ayat di atas, dapat kita analisis yang mendalam yang menghasilkan tentang beberapa hal, yang antara lain sebagai berikut :

1. Asbabun nuzul ayat di atas sebagai berikut:

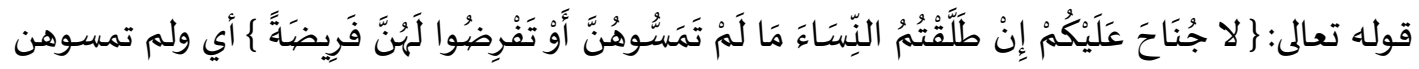

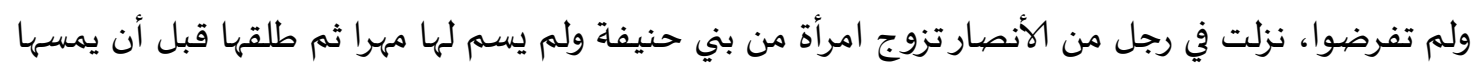

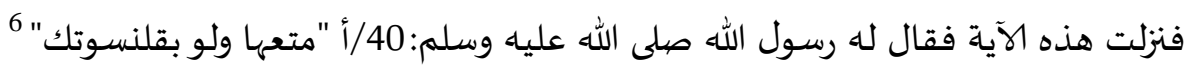

Tidak ada kewajiban membayar (mahar) atas kamu, apabila kamu menceraikan isteriisteri kamu sebelum kamu bercampur dengan mereka dan kamu tidak menentukan maharnya (sebelum akad nikah), maksudnya belum kamu campuri dan belum kamu tentukan jumlah atau benda maharnya. (Penterjemah, kata أو seharusnya dipahami dengan s sebagai huruf 'athof artinya dan bukan atau. Ayat turun disebabkan kejadian pada seorang laki-laki telah menikahi seorang perempuan dari Bani Hanifah, dan tidak disebutkan jumlah maharnya, kemudian dia ceraikan sebelum mencampurinya. Maka turunlah ayat ini. Rasulullah SAW berkata kepada laki-laki tersebut:berikan mut'ah atau pemberian walupun topimu sendiri saja.

2. Asbabun nuzul ini membantu kita untuk mendekati pemahaman, di mana ayat ini turun kasus seorang pria menikahi seorang perempuan, belum menentukan jumlah maharnya sebelum akad nikah, kemudian dia ceraikan, maka rasul perintahkan memberikan mut'ah yaitu peci;

3. Berarti boleh lakukan akad nikah walaupun suami dan isteri belum menentukan berapa dan apa maharnya;

4. Namun secara tersirat, pasti wajib ada mahar apabila ada akad nikah;

5. Apabila mahar boleh belum ditentukan sebelum akad nikah, jadi berapa yang disebut tkan jumlah maharnya, mohon direnungkan kembali;

6ه كـ - 1997 م) .صحمد الحسين بن مسعود البغوي [ المتوفى 516 هـ ] محيي السنة . (معالم التنزيل الناشر : دار طيبة للنشروالتوزيع- الطبعة : الرابعة ، 1417 
6. Dengan demikian mahar adalah syarat akad nikah, tetapi tidak disebutkan mahar saat ijab qabul akad nikah

\section{Ketentuan Ketentuan dalam Menetapkan Mahar}

Mahar ditentukan sebelum akad nikah

1. Dalilnya menentukan jumlah mahar sebelum akad nikah sebagai berikut :

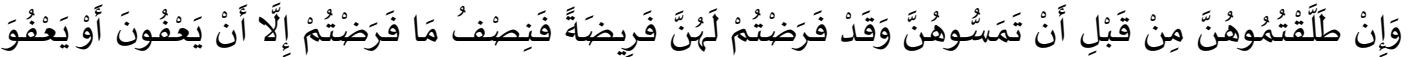

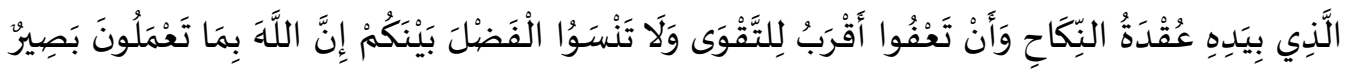

237. "Apabila kamu menceraikan isteri-isterimu sebelum kamu bercampur dengan mereka, padahal sesungguhnya kamu sudah menentukan maharnya, maka bayarlah seperdua dari mahar yang telah kamu tentukan itu, kecuali apabila isteri-isterimu itu mema'afkan atau dima'afkan oleh orang yang memegang ikatan nikah, dan pema'afan kamu itu lebih dekat kepada takwa. Dan janganlah kamu melupakan keutamaan di antara kamu. Sesungguhnya Allah Maha Melihat segala apa yang kamu kerjakan. Ialah suami atau wali. Kalau wali mema'afkan, maka suami dibebaskan dari membayar mahar yang seperdua, sedang kalau suami yang mema'afkan, maka dia membayar seluruh mahar". 7 Dari uraian di atas, dapat dianalisis secara mendalam sehingga menghasilkan sebagai berikut :

a. Boleh ditentukan mahar sebelum akad nikah jumlah atau besarannya, atas dasar sepakat calon suami dan isteri, serta kedua orang tuanya apabila masih ada;

b. Namun dalam ayat di atas tidak ada kata yang menjelaskan wajib disebutkan jumlah mahar saat ijab qobul;

c. Kondisi menentukan mahar sebelum nikah, apabila kasus seorang isteri yang muslimah, sedangkan suaminya masih kapir, dalilnya sebaagi berikut:

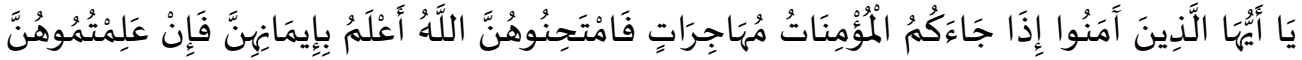

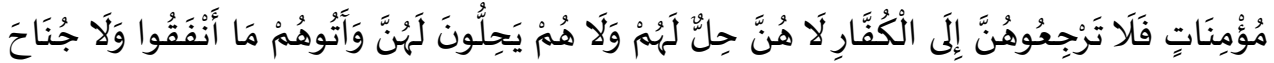

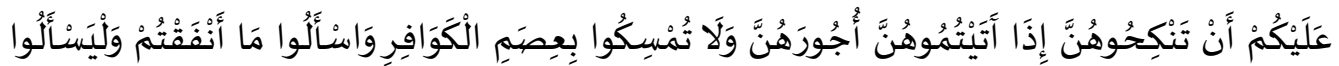

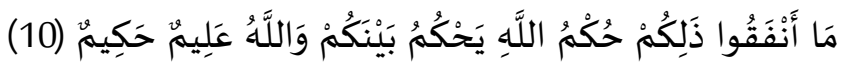

Artinya: "Hai orang-orang yang beriman, apabila datang berhijrah kepadamu perempuan-perempuan yang beriman, maka hendaklah kamu uji (keimanan) mereka. Allah lebih mengetahui tentang keimanan mereka; maka apabila kamu telah mengetahui bahwa mereka (benar-benar) beriman maka janganlah kamu kembalikan mereka kepada (suami-suami mereka) orang-orang kafir. Mereka tiada halal bagi orang-orang kafir itu dan orang-orang kafir itu tiada halal pula bagi mereka. Dan berikanlah kepada (suami suami) mereka, mahar yang telah mereka bayar. Dan tiada dosa atasmu mengawini mereka apabila kamu bayar kepada mereka maharnya. Dan janganlah kamu tetap berpegang pada tali (perkawinan) dengan perempuan-perempuan kafir; dan hendaklah kamu minta mahar yang telah kamu bayar; dan hendaklah mereka meminta mahar yang telah

\footnotetext{
${ }^{7}$ Qs. al-Baqarah, 2:236-237
} 
mereka bayar. Demikianlah hukum Allah yang ditetapkan-Nya di antara kamu. Dan Allah Maha Mengetahui lagi Maha Bijaksana. ${ }^{8}$

d. Non Muslim menikah, cerainya salah satunya masuk Islam demikian juga Muslim suami isteri satu murtad maka wajib cerai;

e. Suami isteri Islam, belum dicampuri suami satu murtad, maka otomatis batal nikah;

f. Menikahi non Muslim haram dalilnya \{Qs, al-Baqarah :22\}

g. Maka iddahnya seperti iddah cerai, apabila hamil sampai melahirkan, apabila masih haid 3 kali haid, apabila monofous 3 bulan;

h. Gunanya menungu apakah ada kesadaran suami yang kapir mau Islam;

i. Apabila selama iddah tidak mau Muslim, maka mereka otomatis cerai karena keislaman isteri;

j. Selama mereka suami dan isteri, apabila ada mahar dikasih suami yang kapir, maka isteri wajib mengembalikan maharnya disamkan dengan tolaq khulu', di mana isteri minta cerai $\{$ Qs. al-Baqarah ayat 229$\}$

k. Dengan demikian isteri memilih duluan mahar ditentukan nikah kedua kepada muslim, apakah cukup biaya mengembalikan mahar kepada suami yang pertama masih kapir;

1. Manfaatnya agar dia suami yang kapir mendapat modal untuk menikah dengan perempuan, mudah-mudahan dapat isteri yang muslimah;

m. Masih wajar isteri membayar maharnya, karena dia sudah menikah dengan seorang muslim yang didambakannya. Kenapa tidak perlu disebutkan jumlah mahar yang disepakati;

1) Apabila disebutkan seolah olah akad nikah seperti jual beli benda;

2) Apabila disebutkan merasa bangga yang besar maharnya, dan merasa hina bagi yang kecil maharnya;

3) Pada gilirannya bahan buah ejekan sesama umat yang mendengarnya;

4) Jadi penomena sebgaian umat, tidak sama jumlah yang diberikan calon suami maharnya dengan yang disebutkan saat ijab qobul;

5) Contohnya pihak calon isteri minta maharnya 50.000.000 tetapi yang disebutkan saat ijab qobulnya kadang 5 gram emas atau seperangkat alat shalat;

6) Akhirnya terjadi pembohongan terprogram, setiap ada ijab qobul akad nikah;

7) Selanjutnya terjadi ajang lomba besaran mahar antara sesama umat Islam;

8) Juga terjadi biaya pesta yang menelan biaya yang cukup mahal;

9) Gunanya sekedar haruan telinga pujian berlebihan, dilarang dalam Islam, seperti pamer, riya dan bangga diri.

\section{Dasar Hukum Mahar}

Dasra hukum mahar seharusnya berdasarkan al-Qur'an dan hadis bukan kewenangan umat atau ulama. Dalil masalah mahar sebagai berikut:

1. Istilah mahar selain sodaq atau jama'nya soduqot \{Qs. an-Nisa' ayat 4 \} adalah kaat 'ujur atau upah hukumnya fardu dalilnya sebagai berikut:

\footnotetext{
${ }^{8}$ Qs. al-Mumtahanah, 60:10.
} 


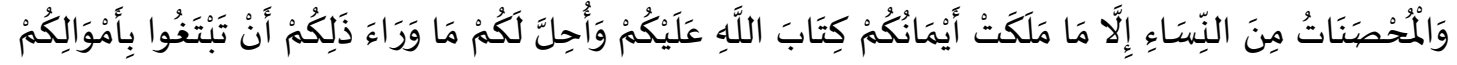

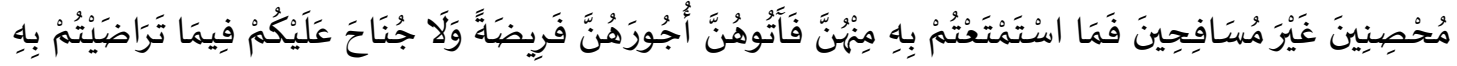

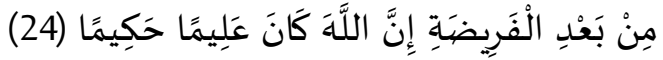

Artinya: "dan (diharamkan juga kamu mengawini) perempuan yang bersuami, kecuali budak-budak yang kamu miliki (Allah telah menetapkan hukum itu) sebagai ketetapan-Nya atas kamu. dan Dihalalkan bagi kamu selain yang demikian (yaitu) mencari isteri-isteri dengan hartamu untuk dikawini bukan untuk berzina. Maka isteriisteri yang telah kamu nikmati (campuri) di antara mereka, berikanlah kepada mereka maharnya atau upahnya (dengan sempurna), sebagai suatu kewajiban; dan tiadalah mengapa bagi kamu terhadap sesuatu yang kamu telah saling merelakannya, sesudah menentukan mahar itu. Sesungguhnya Allah Maha mengetahui lagi Maha Bijaksana. Maksudnya: budak-budak yang dimiliki yang suaminya tidak ikut tertawan bersamasamanya. Ialah: selain dari macam-macam perempuan yang tersebut dalam surat An Nisaa' ayat 23 dan 24. Ialah: menambah, mengurangi atau tidak membayar sama sekali maskawin yang telah ditetapkan". Dari uraian di atas, dapat kita analisis sebagai berikut :

a. Kenapa istilah upah mahar itu? Jawabannya karena isteri telah kerja berat untuk melayani suaminya awal pertamanya dan selanjutnya;

b. Senggama pertama isteri masih ketakutan, namun suami sangat menginginkan dan sangat mendambakannya;

c. Orang yang takut tentu cepat keringat, apalagi melayani suami yang awalnya dikenal saat pinangan;

d. Kerja yang keringat, maka berikan upahnya sebelum kering keringatnya, dalilnya sebagai berikut:

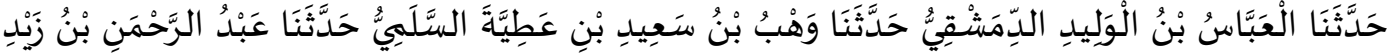

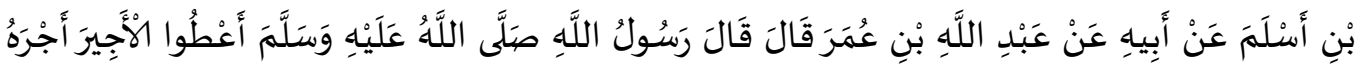

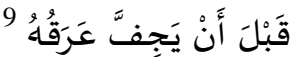

Ibnu Majah - 2434 "Telah menceritakan kepada kami Al Abbas bin Al Walid Ad Dimasyqi berkata, telah menceritakan kepada kami Wahb bin Sa'id bin Athiah As Salami berkata, telah menceritakan kepada kami 'Abdurrahman bin Zaid bin Aslam dari Bapaknya dari Abdullah bin Umar ia berkata, "Rasulullah SAW bersabda: "Berikanlah upah kepada pekerja sebelum kering keringatnya."

2. Apabila kamu telah memberikan mahar atau upahnya maka perempuan tersebut menjadi muhsonah atau sudah menikah benaran atau menjadi tidak perawan lagi, maka harus berikan maharnya sebagai upahnya dalilnya surah al-Maidah ayat 5 sebagai berikut:

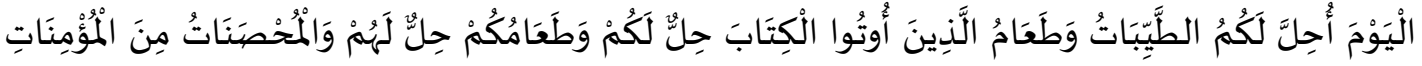

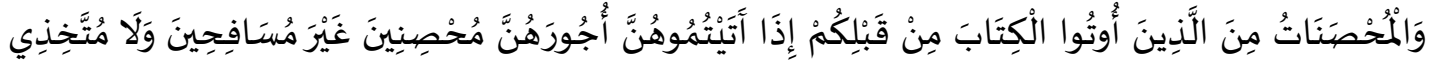

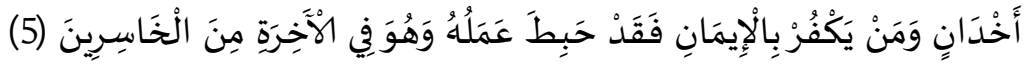

\footnotetext{
${ }^{9}$ Ibn Majah, Sunan Ibn Majah, (Beirut : Dar al-Katib, al-Ilmiyah, 275 H). hlm. 398.
} 
5. "pada hari ini Dihalalkan bagimu yang baik-baik. makanan (sembelihan) orangorang yang diberi Al kitab itu halal bagimu, dan makanan kamu halal (pula) bagi mereka. (dan Dihalalkan mangawini) perempuan yang menjaga kehormatan diantara perempuan-perempuan yang beriman dan perempuan-perempuan yang menjaga kehormatan di antara orang-orang yang diberi Al kitab sebelum kamu, bila kamu telah membayar mas kawin mereka dengan maksud menikahinya, tidak dengan maksud berzina dan tidak (pula) menjadikannya gundik-gundik. Barangsiapa yang kafir sesudah beriman (tidak menerima hukum-hukum Islam) Maka hapuslah amalannya dan ia di hari kiamat Termasuk orang-orang merugi. Ada yang mengatakan perempuan-perempuan yang merdeka". Analisis :

a. Maksud apabila kamu telah membayar maharnya mereka dengan maksud menikahinya, apabila kita sudah bayar maharnya berarti sudah kita campuri, karena nikah hakikatnya adalah senggama bukan sekedar akad nikah;

b. Nikah menghalalkan yang haram dengan syarat dan rukun nikahnya sudah sempurna berdasarkan dalilnya, sakin halalnya haram tidak dihalalkan;

c. Apabila duluan dibayar identik dengan zina, karena berzina duluan dibayar baru lakukan perzinaan, takut perempuannya lari laki-laki yang menzinanya;

d. Apabila selesai senggama baru diberikan suami mahar, takut suami isterinya tidak perawan lagi, pada hal pengakuannya dia perawan;

e. Tidak dengan maksud berzina, menggambarkan apabila mahar diberikan setelah senggama awalnya;

f. Tidak (pula) menjadikannya gundik-gundik atau perempuan simpanan atau selingkuhan sekarang.

3. Menyebutkan pemberian salah, bahkan sampai menyakitikan perasaan tentu semakin salah, dalilnya sebagai berikut:

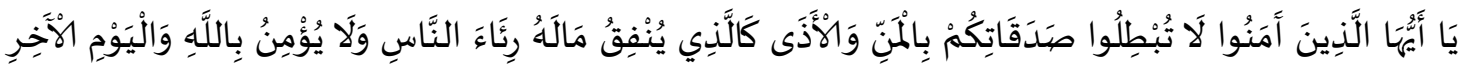

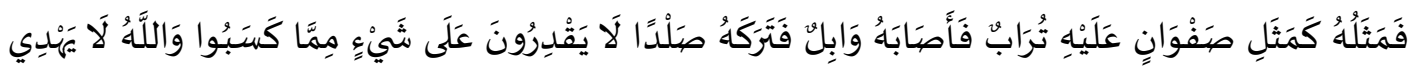

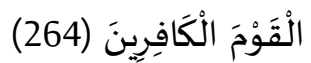

264. "Hai orang-orang yang beriman, janganlah kamu menghilangkan (pahala) sedekahmu dengan menyebut-nyebutnya dan menyakiti (perasaan si penerima), seperti orang yang menafkahkan hartanya karena riya kepada manusia dan Dia tidak beriman kepada Allah dan hari kemudian. Maka perumpamaan orang itu seperti batu licin yang di atasnya ada tanah, kemudian batu itu ditimpa hujan lebat, lalu menjadilah Dia bersih (tidak bertanah). mereka tidak menguasai sesuatupun dari apa yang mereka usahakan; dan Allah tidak memberi petunjuk kepada orang-orang yang kafir. Mereka ini tidak mendapat manfaat di dunia dari usaha-usaha mereka dan tidak pula mendapat pahala di akhirat". Analisis :

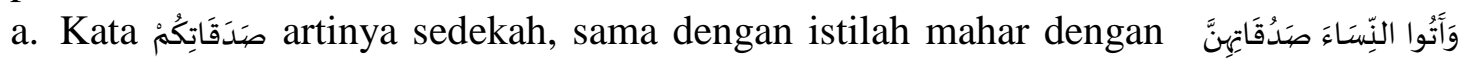

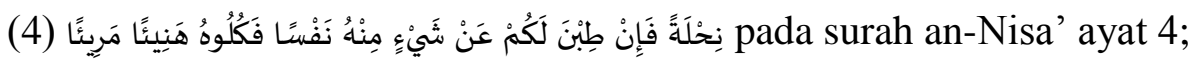

b. Janganlah kamu menghilangkan (pahala) sedekahmu dengan menyebut-nyebutnya dan menyakiti (perasaan si penerima), termasuk menyebutnya saat akad nikah, apabila banyak bangga apabila sedikit menyakiti perasan, menjadi omongan orang banyak; 
c. Seperti orang yang menafkahkan hartanya karena riya kepada manusia, jadi pemberian yang disebutkan menggambarkan sedekah riya, dan menggambarkan manusia yang tidak beriman kepada Allah dan hari kemudian.

\section{E. Mahar Syarat Nikah Bukan Rukun}

Sayarat akad nikah, merupakan serangkaian ibadah yang wajib dikerkajakan sebelum pellaksanaan rukun ibadahnya. Selanjutnya syarat itu masih melekat pada rukunnya. Contohnya syarat solat berwudu' hukumnya wajib. Saat mengerjakan rukun solat kita tetap dalam keadaan berwudu'. Apabila batal wudu' maka batal solat, demikian syarat lainnya seperti tutup aurat, menghadap qiblat, suci badan dan tempat solat dari najis. Dibandingkan dengan puasa, kita tetap dalam keadaan dalam menbatalkan puasa, karena syaratnya menahan diri dari segala yang membatalkan puasa, Islam, balig, jangan haid, jangan sedang nifas, namun syarat itu tidak disebutkan saat puas atau solat, seperti aku puasa aku Islam, aku solat aku sedang dalam wudu'. Dan lainnya dari syarat itu sendiri yang dapat dijadikan bahan analisis mahar syarat akad nikah adalah sebagai berikut :

1. Berdasarkan perbandingan syarat solat dan puasa dengan mahar, di mana mahar itu syarat akad nikah, tidak perlu disebutkan saat ijab qobul akad nikah;

2. Namun mahar sebagai syarat nikah tetap terpaut atau terikat dalam ijab qobul akad nikah sampai kapan suami mampu tetpa menajdi utangnya' kecuali dimaafkan oleh isterinya;

3. Analisisnya dijelaskan dalam al-Quran pada surah al-Baqarah ayat 236 dijelaskan boleh belum ditentukan mahar sebelum akad nikah namun secara tersirat wajib ada mahar apabila sudah diselenggarakan ada akad nikah;

4. Ayat 237 pada suroh al-Baqarah boleh ditentukan jumlah mahar sebelum akad nikah, tetapi penyebutan saat akad nikah tidak dijelaskan apakah disebutkan aau tidak;

5. Ketidak ada penjelasannya dalam ayat di atas, maka yang berwenang menjelaskannya tentu Rasul bukan umat.

Dari pembicaraan yang alot di atas, adalah pertanyaan tentang perlukah penyebutan jumlah mahar sat akad nikah.

a. Penyebutan mahar saat ijab qabul akad nikah tidak perlu penjelasan dalam kitab fikih Malik sebagai berikut:

Ucapan ijab dari wali أَنْكَحْتُكَ بِنْتِ فُفَلَنَة , dalam kitab fikih Maliki, sebagai berikut: 


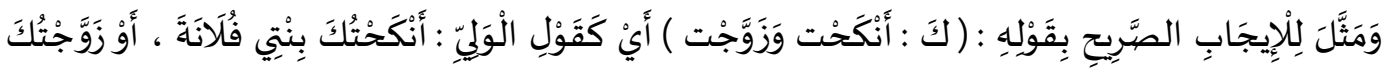

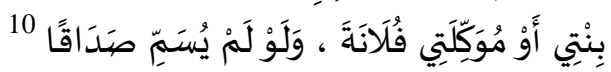

Contoh ucapan Ijab dari wali yang shohih adalah : Aku nikahkan kepadamu Putriku si Fulanah walaupun tidak menyebutkan maharnya, apabila perwakilan wali nikah lafazh ijabnya: Aku perwakilan meniikahkan kepadamu si anu binti sianu, atau perwakilkan menikahkan fulanah (sebut namanya) tanpa menyebut jumlah maharnya.

b. Boleh juga dengan contoh lafazh langsung wali nasab ( أنَكَحْتُكَ حَفْصَةَ بِنْتَ عُمَرَ) artinya:

“Aku nikahkan kepadamu Hafshoh putri 'Umar

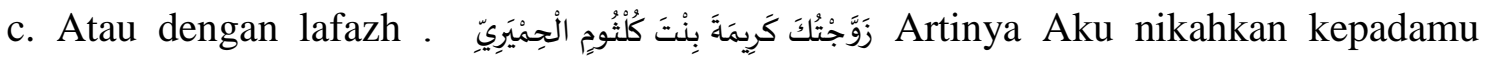
Karimah putri Kultsum al-Himri). Contoh lafazh akad nikah dalam hadis tanpa menyebutkan jumlah mahar adalah أَنْحَنْنُكَ حَفْصَةَ بِنْنَ عُعَرَ dalilnya sebagai berkut:

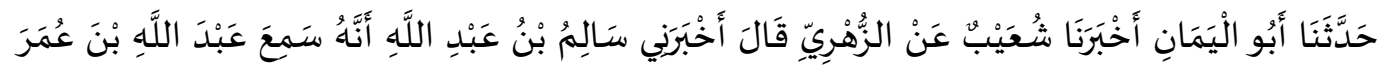

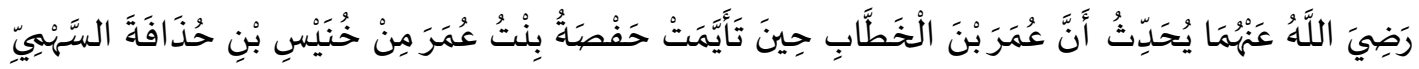

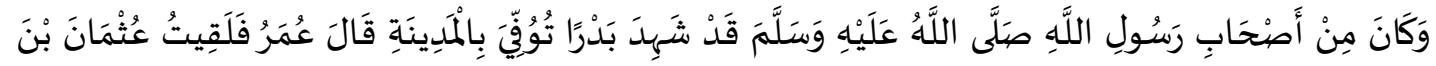

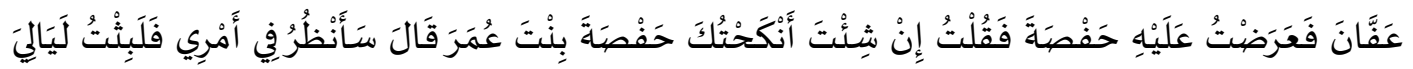

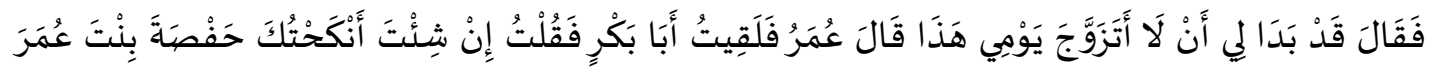

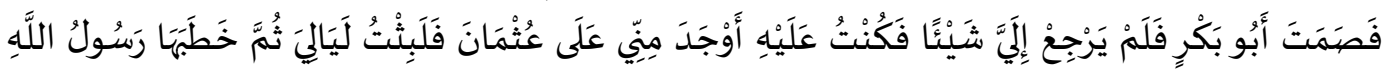

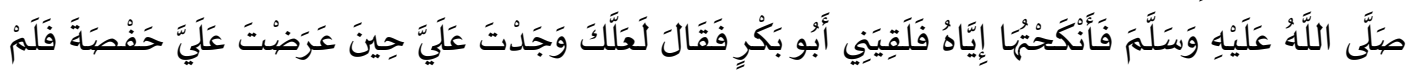

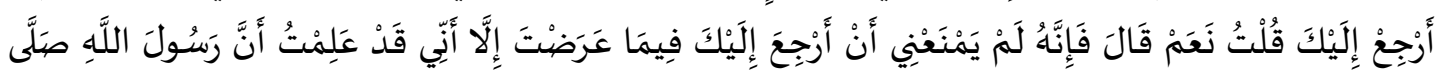

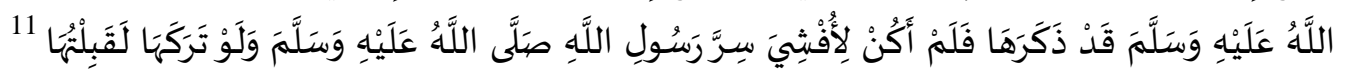

Bukhari - 3704 “Telah menceritakan kepada kami Abu Al Yaman telah mengabarkan kepada kami Syu'aib dari Az Zuhri dia berkata, telah mengabarkan kepadaku Salim bin Abdullah bahwa dia mendengar Abdullah bin Umar radliallahu 'anhuma bercerita, bahwa Umar bin Khattab berkata ketika Hafshah binti Umar menjanda dari Khunais bin Hudzafah As Sahmi -ia termasuk di antara sahabat Rasulullah SAW yang ikut serta dalam perang Badr dan meninggal di Madinah-, Umar berkata, "Maka aku datangi Usman bin 'Affan dan kutawarkan Hafshah kepadanya. Aku berkata, "Apabila engkau mau, maka aku akan menikahkan kepadamu dengan Hafshah binti Umar." Utsman hanya memberi jawaban, "Aku akan melihat perkaraku dulu, " aku lalu menunggu beberapa malam, kemudian ia menemuiku dan berkata, "Nampaknya aku tidak akan menikah pada saat ini." Umar berkata, "Kemudian aku menemui Abu Bakr, kukatakan padanya, "Apabila engkau menghendaki, maka aku akan menikahkan kepadamu dengan Hafshah binti Umar."

\footnotetext{
${ }^{10}$ Hasyiah ash-Showi 'ala asy-Sayrahi ash-Shogir, (Mesir: Kairo,tt), Mauqi' al-Islam al-Kitab Masykul wa Marqom Aliya Ghoiru Muwafiq Lilmathbu'), http://www.al-islam.com , hlm. 427.

${ }^{11}$ Al-Bukhari, Sahih al-Bukhari, (Beirut: Dar al-Fikr,t.t). hlm. 367.
} 
Abu Bakar hanya terdiam dan tidak memberi jawaban sedikitpun kepadaku. Dan kemarahanku kepadanya jauh lebih memuncak daripada kepada Utsman. Lalu aku menunggu beberapa malam, ternyata Rasulullah SAW meminangnya. Maka aku menikahkannya dengan beliau. Kemudian Abu Bakr menemuiku dan berkata, "Sepertinya engkau marah kepadaku ketika engkau menawarkan Hafshah kepadaku dan aku tidak memberi jawaban sedikitpun." Aku menjawab, "Ya." Abu Bakr berkata, "Sebenarnya tidak ada yang menghalangiku untuk memberi jawaban kepadamu mengenai apa yang engkau tawarkan kepadaku, kecuali aku mengetahui bahwa Rasulullah SAW sering menyebut-nyebutnya, dan tidak mungkin aku akan menyebarkan rahasia Rasulullah SAW. Kalaulah beliau meninggalkannya, tentu aku akan menerima tawaranmu."

\section{Penguat :}

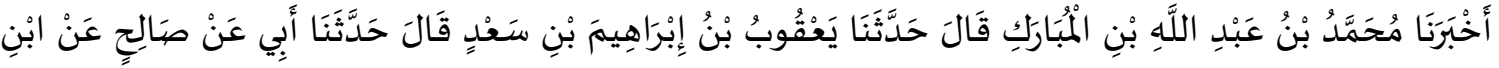

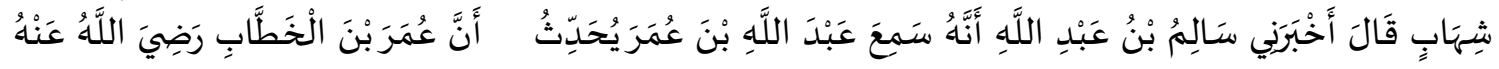

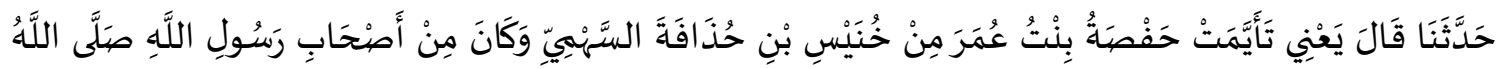

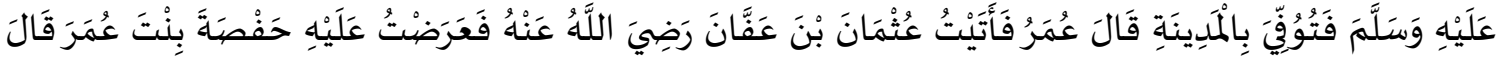

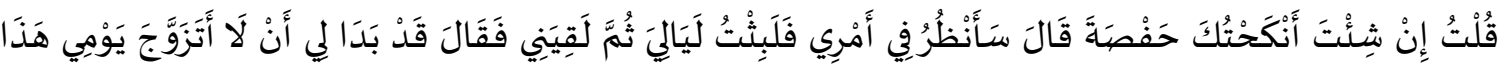

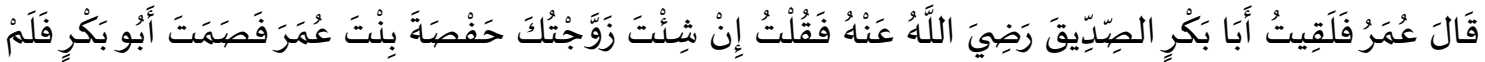

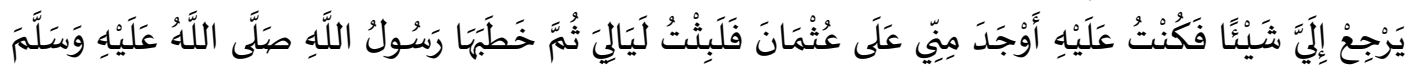

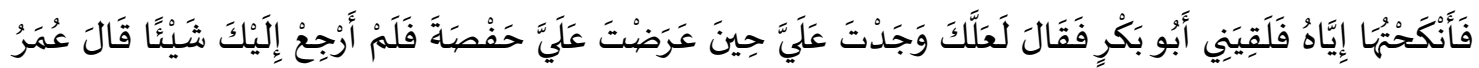

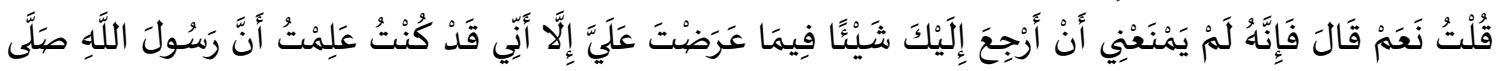

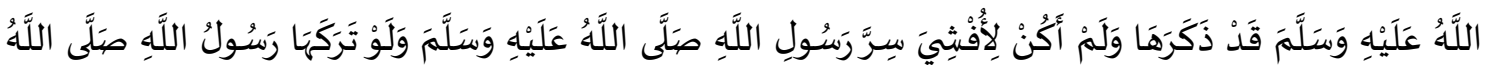

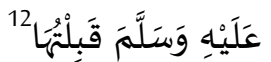

NASAI - 3207 “Telah mengabarkan kepada kami Muhammad bin Abdullah bin Al Mubarak, ia berkata; telah menceritakan kepada kami Ya'qub bin Ibrahim bin Sa'd, ia berkata; telah menceritakan kepada kami ayahku dari Shalih dari Ibnu Syihab, ia berkata; telah memberitakan kepadaku Salim bin Abdullah bahwa ia pernah mendengar Abdullah bin Umar menceritakan bahwa Umar bin Khathab radliallahu 'anhu menceritakan kepada kami, ia berkata; Hafshah binti Umar menjanda dari Khunais bin Hudzafah As Sahmi, ia termasuk diantara sahabat Rasulullah SAW dan meninggal di Madinah. Umar berkata; Maka saya datangi Usman bin 'Affan radliallahu 'anhu dan kutawarkan Hafshah binti Umar. Umar berkata; saya katakan; 'Apabila engkau selera, saya nikahkan engkau dengan Hafshah. Usman hanya memberi jawaban 'Saya akan melihat perkaraku dahulu, saya perlu menunggu beberapa malam', kemudian ia menemuiku dan berkata; 'nampaknya saya tidak akan menikah pada saat ini.' Umar berkata; kemudian saya menemui Abu Bakr Ash Shiddiq radliallahu 'anhu, dan saya katakan; apabila engkau menghendaki, saya nikahkan engkau dengan Hafshah binti Umar. Abu Bakar hanya terdiam dan tidak membawa jawaban sedikitpun kepadaku. Dan kemarahanku kepadanya jauh lebih memuncak daripada kepada Usman. Lalu saya menunggu beberapa malam,

\footnotetext{
${ }^{12}$ An-Nasai, Sunan An-Nasai, (Semarang: Maktabah wa Matba'ah, 279 H) . hlm. 391.
} 
kemudian Rasulullah SAW meminangnya. Maka saya menikahkannya dengan Rasulullah SAW. Kemudian Abu Bakr menemuiku dan berkata; Sepertinya engkau marah kepadaku ketika engkau menawarkan Hafshah kepadaku dan saya tidak membawa jawaban sedikitpun. Umar berkata; saya katakan; 'Iya.' Abu Bakr berkata; sebenarnya tidak ada yang menghalangiku untuk memberi jawaban kepadamu mengenai apa yang engkau tawarkan kepadaku, kecuali saya telah mengetahui bahwa Rasulullah SAW sering-sering menyebut-nyebutnya, dan tidak mungkin saya akan menyebarkan rahasia Rasulullah SAW. Kalaulah beliau meninggalkannya, tentu saya menerimanya.

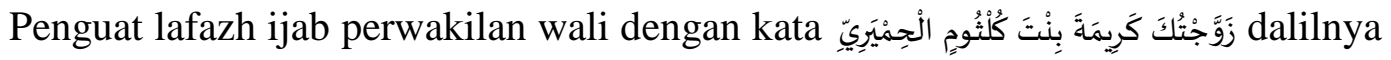
sebagai berikut :

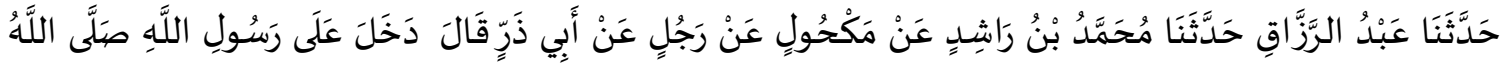

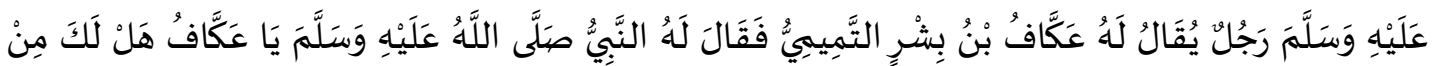

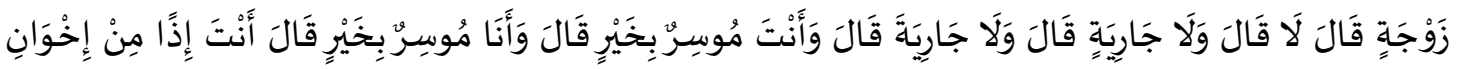

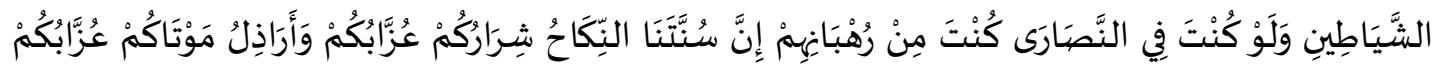

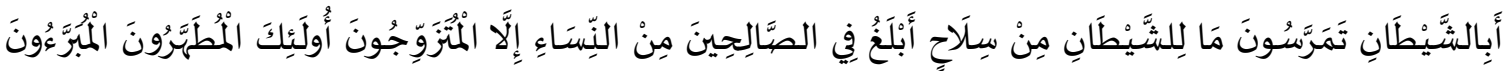

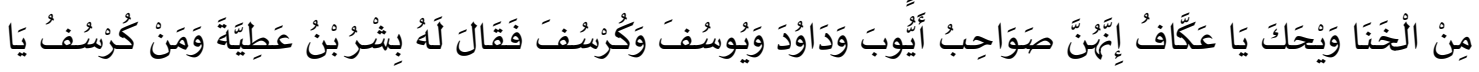

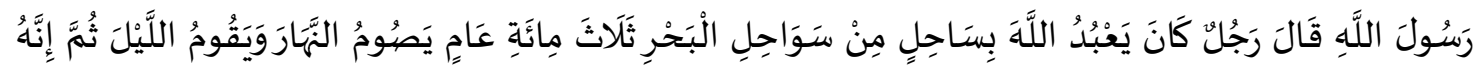

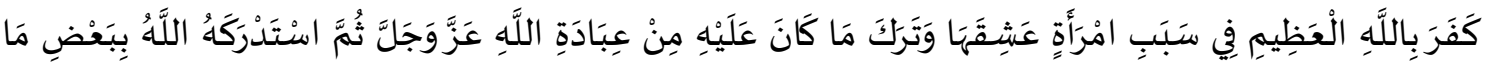

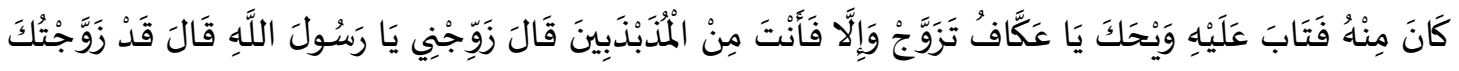

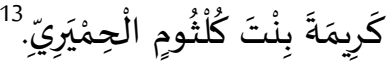

Ahmad - 20477 "Telah menceritakan kepada kami Abdurrazaq telah menceritakan kepada kami Muhammad bin Rasyid dari Makhul dari seseorang dari Abu Dzar dia berkata, "Seorang laki-laki yang bernama Akkaf bin Bisyr At Taimi datang menemui Rasulullah SAW. Kemudian Nabi SAW bertanya kepadanya: "Wahai 'Akkaf, apakah kamu mempunyai seorang isteri?" Dia menjawab, "Tidak." Nabi bertanya lagi; "Tidak juga seorang budak perempuan?" Dia kembali menjawab, "Tidak juga budak perempuan." Nabi bersabda: "Engkau dalam keadaan lapang?" Ia menjawab, "Ya, saya dalam keadaan lapang." Nabi SAW pun bersabda: "Kalau begitu kamu termasuk saudarasaudara setan, seandainya kamu orang Nasrani pasti kamu termasuk para pendeta mereka. Sesungguhnya sunnah kami adalah menikah, orang yang paling buruk di antara kalian adalah orang yang masih bujang, dan mayit kalian yang paling hina adalah orang yang meninggal dalam keadaan masih bujang. Apakah kalian hendak melawan setan padahal tidak ada senjata setan yang paling ampuh untuk melawan orang-orang shalih selain perempuan? Kecuali bagi orang-orang yang sudah beristeri mereka itulah orangorang yang disucikan lagi dihindarkan dari perbuatan keji. Celakalah kamu wahai 'Akkaf! Sesungguhnya para perempuan itu adalah pendamping-pendamping Ayyub, Daud, Yusuf dan Kursuf." Bisyr bin 'Athiyah lalu bertanya kepada beliau, "Siapa Kursuf itu wahai Rasulullah?" Beliau menjawab: "Dia adalah seorang lelaki yang beribadah kepada Allah di tepi laut selama tiga ratus tahun; siangnya dia berpuasa dan malamnya

\footnotetext{
${ }^{13}$ Ahmad bin Hanbal, Musnad Ahmad, (Beirut : Dar al-Katib, al-Ilmiyah, 275 H ). hlm. 491.
} 
dia shalat, namun kemudian ia kafir kepada Allah yang Maha Agung disebabkan seorang perempuan yang dia sukai, dan dia tinggalkan kebiasaan ibadahnya kepada Allah SWT. Kemudian Allah mengembalikan dia menjadi baik sehingga dia bertaubat. celaka kamu wahai 'Akkaf, hendaklah engkau menikah! Apabila tidak berarti kamu termasuk orang yang ragu ragu." Kemudian 'Akkaf berkata, "Nikahkan aku wahai Rasulullah!" Beliau lalu bersabda: "Aku nikahkan kamu dengan Karimah binti Kultsum Al Himyari. Lafazh akad nikah perwakilan. Apabila perwakilan maka lafazhnya disebutkan: Aku perwakilan: Aku nikahkan kepadamu ... (sebutkan nama calon isteri), binta ... (harus disebutkan nama wali aslinya).

Lafazh Qobul :

Lafazh qabul dari calon suami قَبَلْتُ نِكَاحَهَا أَوْنَوْرِيجَهَا (artinya Aku terima nikahnya, penjelasannya sebagai berikut:

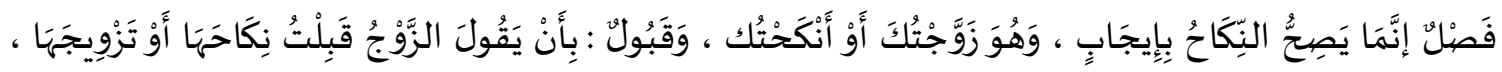

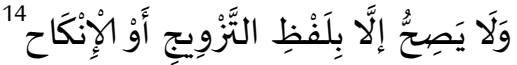

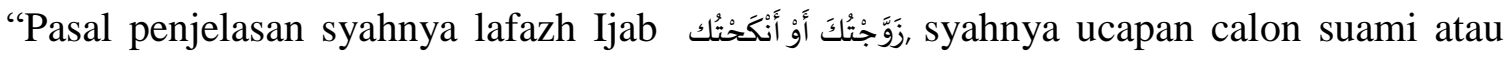

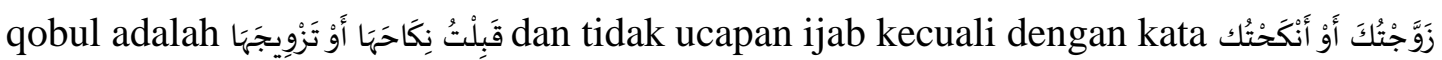

\section{Catatan:}

1. Dalam ilmu nahwu dan shorf, kembali dhomir (kata ganti) sangat boleh dipakai, kita perhatikan ayat dan hadis;

2. Jadi kata نِكَاحَها adalah nama yang disebutkan oleh wali yaitu binti atau putriku sianu

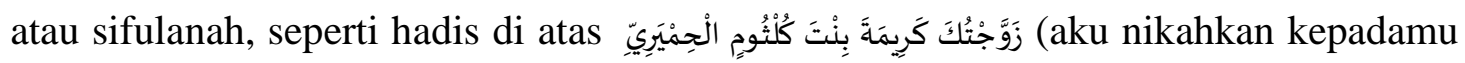
Karimah binti Kalstum al-Himyari), berarti kata ه-nya kembali kepada Karimah binti Kalstum al-Himyari, demikian juga contoh hadis di atas yaitu أنْكَحْتُكَ حَفْصَنَة بِنْتَ عُمَرَ, yang dimaksudkan kata ه-nya adalah Hafshoh putri 'Umar;

3. Sebaiknya calon suami dan wali dilatih dulu mengucapkan ijab dan qobulnya, agar terhindar kesalahan saat berlangsungnya akad nikah. Apabila diperkirakan kurang mampu, sebaiknya ditulis agar mudah membacanya, jauh dari salah dan geroginya

\section{Waktu Penyerahan Mahar :}

1. Ayat di atas menjelaskan bahwa Nabi Syu'aib memberikan upah kepada Musa berupa kambing yang banyak yang diperuntukkan untuk mahar calon isterinya serta modal kerja selanjutnya setelah menikah dalilnya sebagai berikut:

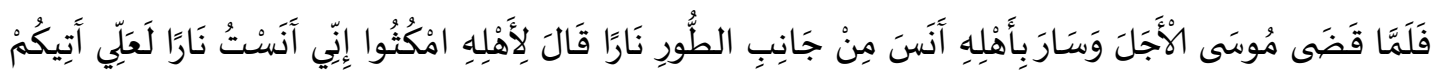

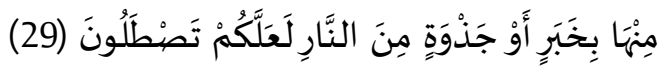

\footnotetext{
${ }^{14}$ Al-Mughni al-Muhtaj ila Ma'rifati Alfazh al-Manjhaj, ( Mesir: Kairo, al-Kitab Masykul wa Marqom Aliya Ghoiru Muwafiq Lilmathbu', Muqi, al-Islam, http://www.al-islam.com, Juz 12, tt) hlm. 91
} 
29. "Maka tatkala Musa telah menyelesaikan waktu yang ditentukan dan dia berangkat dengan keluarganya, dilihatnyalah api di lereng gunung ia berkata kepada keluarganya: "Tunggulah (di sini), sesungguhnya aku melihat api, mudah-mudahan aku dapat membawa suatu berita kepadamu dari (tempat) api itu atau (membawa) sesuluh api, agar kamu dapat menghangatkan badan." Setelah Musa a.s. menyelesaikan perjanjian dengan Syu'aib a.s. ia berangkat dengan keluarganya dengan sejumlah kambing yang diberi mertuanya, maka pada suatu malam yang sangat gelap dan dingin Musa a.s. tiba di suatu tempat tetapi setiap beliau menghidupkan api, api itu tidak mau menyala. Hal itu sangat mengherankan Musa maka ia berkata kepada istrinya sebagai tersebut dalam ayat 29 ". ${ }^{15}$

2. Timbul permasalahan kapan diberikan yang pasti oleh Musa kepada Isterinya, tidak ada lafazh yang menjelaskannya dalam ayat ini;

3. Waktunya setelah menggauli awal, dalilya surah al-Baqarah ayat 236, 237 dan an-Nisa ayat 24 ;

4. Ayat di atas diperjelas dengan hadis berikut tentang waktu penyerahan mahar kepada isteri:

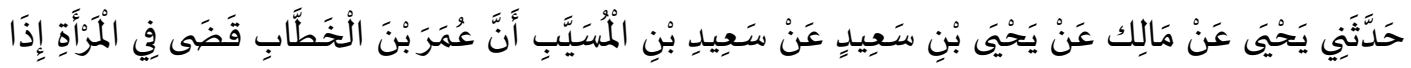

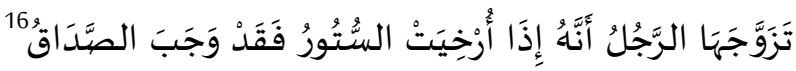

Malik - 971 “Telah menceritakan kepadaku Yahya dari Malik dari Yahya bin Sa'id dari Sa'id bin Musayyab bahwa Umar bin Khattab memberi putusan tentang perempuan yang telah dinikahi oleh seorang laki-laki: "Apabila tirai telah diturunkan, maka mahar wajib dibayarkan."

Maksud turun tirai, tentu suami isteri akan melakukan senggama, bukan hanya sekedar tidur saja, kecuali saat haid. Berarti apabila sudah senggama maka wajb mengasih mahar.

\section{Penguat :}

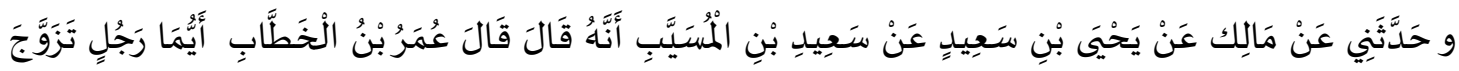

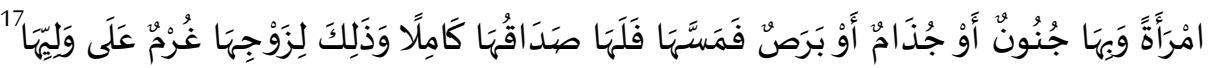

Malik - 969 “Telah menceritakan kepadaku dari Malik dari Yahya bin Sa'id dari Sa'id bin Musayyab ia berkata; Umar bin Khattab berkata; "Laki-laki mana saja yang menikahi perempuan yang terkena gila, atau lepra, atau kusta, lalu ia menyetubuhinya, maka perempuan itu berhak mendapatkan mahar secara penuh. Dan hal itu berakibat walinya yang wajib menanggung hutang atas suaminya."

Penguat:

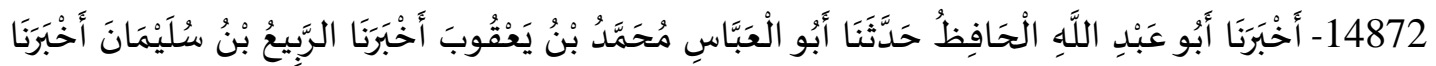

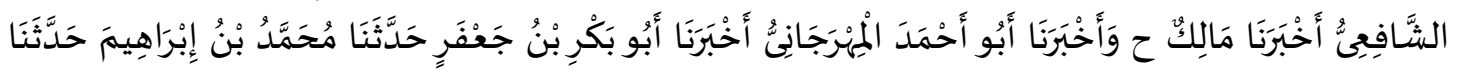

\footnotetext{
${ }^{15}$ Qs. al-Qashash, 28:29.

${ }^{16}$ Malik, al-Muwaththo', (Beirut: Dar al-Fikr,t.t). hlm. 497.

${ }^{17}$ Ibid., hlm.752.
} 


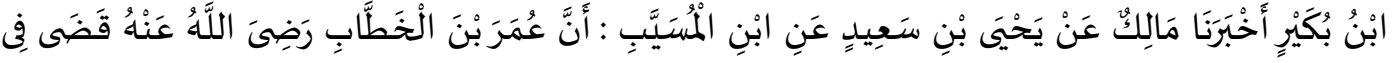

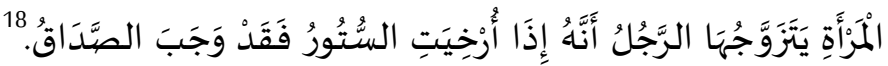

"Mengkhabarkan kepada kami Abu Abdillah al-Hafizh menceritakan kepada kami Abu al-'Abbas Muhammad bin Ya'qub mengkhabarkan kepada kami ar-Robi'bin Sulaiman mengkhabarkan kepada kami asy-Syafii mengkhabarkan kepada kami Malik dan mengkhabarkan kepada kami dan mengkhabarkan kepada kami Abu Ahmad alMihrojaniy mengkhabarkan kepada kami Abu Bakar bin Ja'far menceritakan kepada kami Ibn Bukair mengkhabarkan kepada kami Malik dari Yahya bin Sa'id dari Ibn alMusayyab: bahwa Umar bin Khottob rodiyAllahu 'anhu memberi putusan tentang perempuan yang telah dinikahi oleh seorang laki-laki: "Apabila tirai telah diturunkan, maka mahar wajib dibayarkan"

Analisis:

1. Jadi pemberian mahar oleh suami setelah senggama awal, agar isteri tidak ada kesempatan membodohi calon suaminya;

2. Bahwa dia katanya perawan pada hal bukan lagi, maka awal malam pertama dia bilang sama suami, aku sedang haid, antarkan aku pualng sementara ke umah orangtuaku;

3. Setelah habis masa haidku aku beri tahu agar abang menjemput saya;

4. Ternayata dia lari atau kabur menikah dengan laki-laki lain;

5. Karena sudah dapat akta nikah sebagai tanda janda terhormat, dan sudah mendapat mahar sekian juta;

6. Kepada calon suami saat awal malam pertama bilang sama isteri, apabila kamu nati ternyata masih perawan maka semua mahr ini milikmu, nmaun apabila tidak maka anda tidak ada hakmu sedikitpun;

7. Yakinlah anda apabila masih perawan maka dia mau dites, apabila tidak tentu dia tidak mau dites;

8. Cara mentesnya, ambil sarung tangan terbuat dari karet tipis, baru masukkan jari kelingkingmu, apabila teriak benaran dan kesakitan yang amat, maka masukkan lagi induk jarimu tentu dia tambah sakit;

9. Atau yang peraktisnya, saat pinangan dilihatkan sama pihak medis yang jujur atas pilihan calon suami apakah masih perawan atau tidak.

\footnotetext{
أبابو بكر أحمد بن الحسين بن علي البيقي. السنن الكبارى وفي ذيله الجوهر النقي .( الناشر : مجلس دائرة المعارف النظامية الكائنة في الهند ببلدة حيدر آباد الطبعة : الأولى . 1344 هـ) ص. 384. 
---Volume 5 Nomor 1 Edisi Januari - Juni 2019

\section{F. Penutup}

1. Sejarah mahar sejak Nabi Syu'aib memberikan kesempatan untuk pekerja selama 8 sampai tahun;

2. Proses mahar sejak peminangan, boleh tidak ditentukan namun secara tersirat pasti ada mahar apabila sudah ada ijab qobul, boleh juga ditentukan sebelum akad nikah;

3. Besaran mahar sesuai dengan kemampuan calon suami;

4. Dasar hukumnya bersumber dari al-Quran dan hadis;

5. Mahar adalah syarat nikah bukan rukun nikah;

6. Syarat suatu ibadah dilakukan sebelum mengamalkan rukun nikah;

7. Apabila syarat sudah selesai masalahnya, tinggal pemberiannya sesudah awal senggama suami dan isteri;

8. Apabila disebutkan jumlah mahar terjadi bangga diri apabila besar jumlahnya;

9. Apabila sedikit terjadi rasa hina diri terutama isteri dan keluarganya dan pihak suami;

10. Seolah-olah kaya membeli barang berharga apabila disebut harganya;

11. Menyebutkan pemberian salah, bahkan sampai menyakitikan perasan tentu semakin salah;

12. Menyebutkan mahar atau sedekah menggambarkan sedekah riya, tidak beriman kepada Allah dan hari kemudian;

13. Mahar dibayar suami setelah menggauli awal pertama.

\section{DAFTAR PUSTAKA}

Ahmad bin Hanbal, Musnad Ahmad, Beirut : Dar al-Katib, al-Ilmiyah, 275 H.

Al-Bukhari, Sahih al-Bukhari, Beirut: Dar al-Fikr,t.t.

Al-Mughni al-Muhtaj ila Ma'rifati Alfazh al-Manjhaj, Mesir: Kairo, al-Kitab Masykul wa Marqom Aliya Ghoiru Muwafiq Lilmathbu', Muqi, al-Islam, http://www.alislam.com, tt.

Alquranul Karim.

An-Nasai, Sunan An-Nasai, Semarang: Maktabah wa Matba'ah, 279 H.

Hasyiah ash-Showi 'ala asy-Sayrahi ash-Shogir, Mesir: Kairo,tt. Mauqi' al-Islam alKitab Masykul wa Marqom Aliya Ghoiru Muwafiq Lilmathbu'), http://www.alislam.com.

Gunawan, Hendra,. Karakteristik Hukum Islam, Jurnal Al-Maqasid; Jurnal Ilmu Kesyariahan dan Keperdataan Fakultas Syariah dan Ilmu Hukum IAIN Padangsidimpuan, Vol. 4 No. 2. Edisi Juli-Desember 2018. 


\section{-Jurnal El-Qanuny}

---Volume 5 Nomor 1 Edisi Januari - Juni 2019

Ibn Majah, Sunan Ibn Majah, Beirut : Dar al-Katib, al-Ilmiyah, 275 H.

Malik, al-Muwaththo', Beirut: Dar al-Fikr,t.t

أبو بكر أحمد بن الحسين بن علي البيهقي. السنن الكبرى وفي ذيله الجوهر النقي.( الناشر : مجلس دائرة المعارف

النظامية الكائنة في الهند ببلدة حيدر آباد الطبعة : الأولى - 1344 هـ)

أبو محمد الحسين بن مسعود البغوي [ المتوفى 516 هـ ] .محيي السنة. (معالم التنزيل الناشر :دار طيبة للنشر

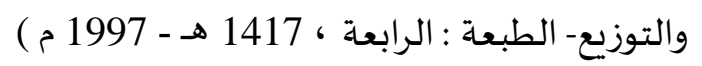

